\title{
Study on the Influence of Furnace Arch Structure on the Combustion Characteristics of Chain Furnace
}

\author{
Shan Jiang ${ }^{1,2}$, Wei Lv ${ }^{1, *}$, Wenxue Gao ${ }^{1}$, Guoli Qi ${ }^{2}$, Songsong Zhang ${ }^{2}$ and Yaqing $\mathrm{Li}^{3}$ \\ ${ }^{1}$ NO.52,Xuefu Road, Nangang County, Harbin City, Harbin University of Science and Technology, Heilongjiang Province, \\ P.R. China, 150080 \\ ${ }^{2}$ Building 2, Hepingjie, Xiyuan, Chaoyang District, Beijing, P.R. China. 100029 \\ ${ }^{3}$ The compound of Huanbao, the road of Xinping Wang Wei two, Datong mining area of Shanxi \\ *Corresponding author
}

\begin{abstract}
In order to study the various furnace arch structure and air distribution on combustion characteristics of chain boiler, based on computational fluid dynamics theory, using numerical simulation method, a three-dimensional physical model for QXL1.4-0.7/95/70-AII type hot water boiler is established, and dividing the grid, setting the boundary conditions, then the process of flue gas flow and combustion were simulated, obtained the temperature field and concentration field in the furnace. The results show that the increase of the length of the front arch and the decrease of the front arch height have a positive effect on the ignition of the fuel; the increase of the back arch cover length and the decrease of the rear arch inclination have the same effect on the ignition and burnout of the fuel The influence of the length of the back arch over the length of the front arch is greater than that of the front arch, and the height of the back arch has little effect on the length of the back arch. In contrast, the front arch is smaller than the rear arch.
\end{abstract}

Keywords-chain furnace; combustion; furnace arch; numerical simulation

\section{INTRODUCTION}

Chain furnace is widely used in industrial boilers in China, but its operation efficiency is low, and the pollution is serious. The furnace arch is the key part of the chain grate combustion. The optimization of the furnace arch structure is of great significance to improve the combustion efficiency of the chain furnace. However, the design of the furnace arch is still using the empirical design method, the lack of theoretical prediction model. In order to solve this problem, the different chamber of a stove conditions of combustion numerical model is established, which provides a scientific method for the design of furnace arch.

At present, the numerical simulation of large-scale power plant boiler has obvious progress, but the numerical simulation technology of the layer combustion boiler is still backward. Domestic researchers have done some research on the simulation of the layer combustion furnace, but because of the difficulty of modeling the coal bed, generally only studied the cold flow field in the furnace or homogeneous combustion of the flue gas in the furnace [1]. For example, a study of Jizhuang WANG, Jifeng CHU, jingru BAI, huanqun QIAN[2-5] . The research progress of layer combustion model in foreign countries is still in the one-dimensional model, such as the research of Gupta R P etc[6-15]. In the process of reforming and designing the chain furnace. firstly, the numerical simulation of the combustion process in the furnace is carried out, which can provide the theoretical basis for the reform and design of the boiler.

This paper analyzed the combustion process of the QXL1.4-0.7/95/70-AII type hot water boiler in turbulent flow and combustible gas, the flow field distribution, temperature field distribution and composition distribution of the combustion chamber with different furnace arch dimensions are obtained.

\section{PHYSICAL MODEL}

In this paper, a physical model of boiler chain boiler with QXL1.4-0.7/95/70-AII model is established .The length, width and height of the chamber of furnace were $3.32 \mathrm{~m}, 1.13 \mathrm{~m}, 3 \mathrm{~m}$.

\section{NUMERICAL CALCULATION}

\section{A. Mesh Partition}

In this paper, the numerical simulation model is built and the mesh generation by Gambit. Grid spacing selection 30mm, the number of grids is 1588793. Grid partition of computational region is shown in Figure 1.This text only simulate the flow and combustion of mixed gas in the furnace. The inlet of the chamber of a furnace is selected on the fuel surface, since the area behind the anti slag tube has little effect on the combustion of combustible gases, it only affects the heat transfer, in order to reduce the number of grids and save the time needed for numerical calculation, select the front of the anti slag tube as an outlet.

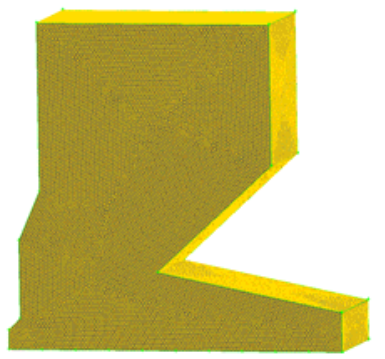

FIGURE I. GRID PARTITION OF COMPUTATIONAL REGION 


\section{B. Mathematical Model}

This text, the Realizable $k-\varepsilon$ model is used to describe the gas turbulent transport, P-1 radiation model is used to describe radiation heat transfer, the wall function model is used for the turbulence near the wall, the eddy dissipation model is used to describe the gas phase combustion in the furnace.

\section{Boundary Condition}

1) Setting the boundary conditions of the furnace inlet

Set the inlet speed and components, and set the inlet flue gas temperature

2) Setting the boundary conditions of the furnace outlet

The furnace outlet is set as the pressure outlet, assuming that the negative pressure value of the furnace outlet is $-30 \mathrm{~Pa}$.

\section{3) Wall boundary condition}

Set the arch boundary adiabatic boundary condition, the furnace wall is of constant temperature, the blackness value is 0.8 .

\section{CALCULATION RESUlts ANALYSIS}

\section{A. Effect of Front Arch on Combustion}

1) The influence of the overlay length of the front arch on the combustion

The effect of the length of the front arch on the temperature of the front arch is shown in Figure 2. It can be seen that the average temperature of the front arch increases with the length of the front arch extending from $0.1 \mathrm{~L}$ to $0.3 \mathrm{~L}$.

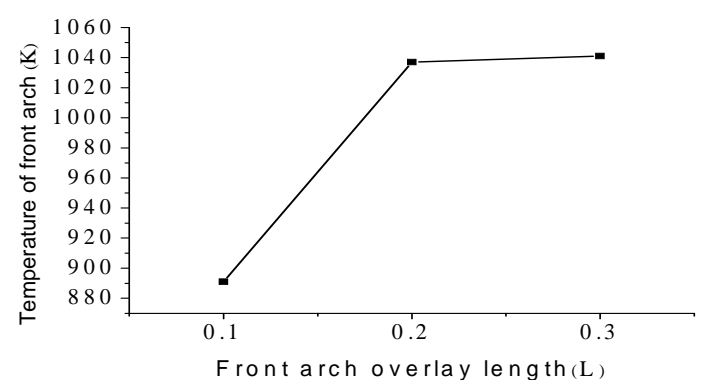

FIGURE II. THE TEMPERATURE OF THE FRONT ARCH UNDER THREE DIFFERENT LENGTH OF FRONT ARCH

The concentration distribution of $\mathrm{O} 2, \mathrm{H} 2, \mathrm{CO}$ and $\mathrm{CO} 2$ in the outlet of the furnace under different overlay length of the front arch is shown in Figure 3, figure 4, figure 5 and Figure 6 respectively. On the whole, the concentration of $\mathrm{O} 2$, , $\mathrm{H} 2$ and $\mathrm{CO}$ in the furnace outlet decreased with the increase of the length of the front arch, and the $\mathrm{CO} 2$ concentration decreased with the increase of the length of the front arch, which indicated that more combustible gases were reacted.

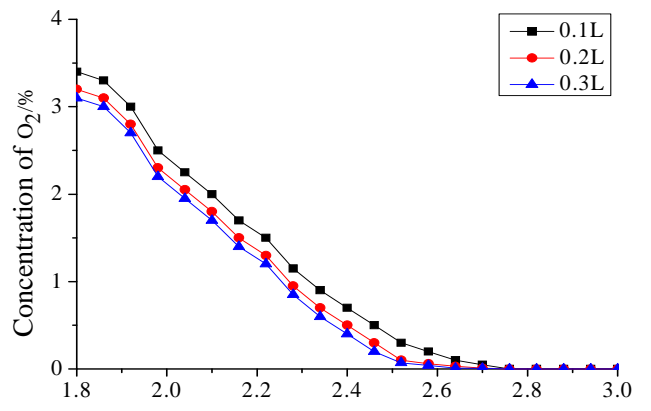

Distance from furnace exit to coal seam surface/m

FIGURE III. $\mathrm{O}_{2}$ DISTRIBUTION OF FURNACE OUTLET UNDER THREE KINDS OF FRONT ARCH LENGTH

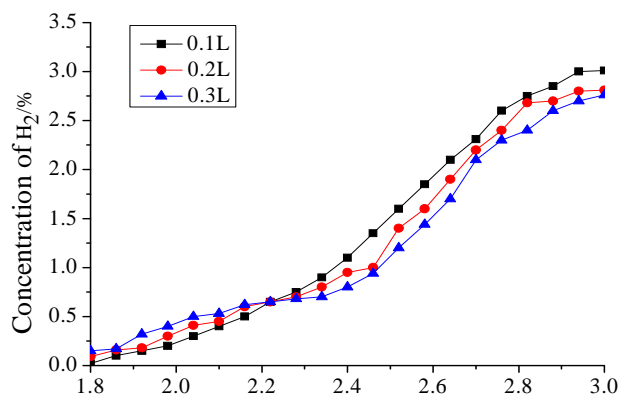

Distance from furnace exit to coal seam surface/m

FIGURE IV. $\mathrm{H}_{2}$ DISTRIBUTION OF FURNACE OUTLET UNDER THREE KINDS OF FRONT ARCH LENGTH

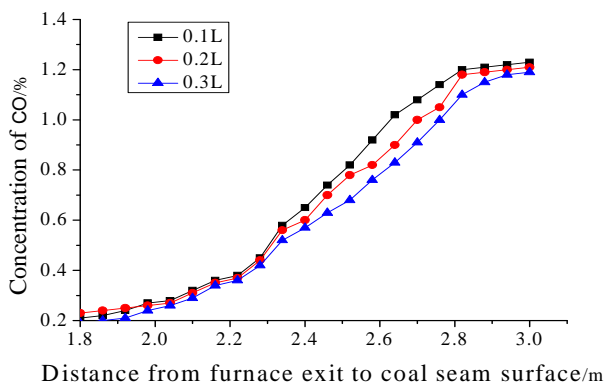

FIGURE V. CO DISTRIBUTION OF FURNACE OUTLET UNDER DIFFERENT OVERLAY LENGTH OF FRONT ARCH

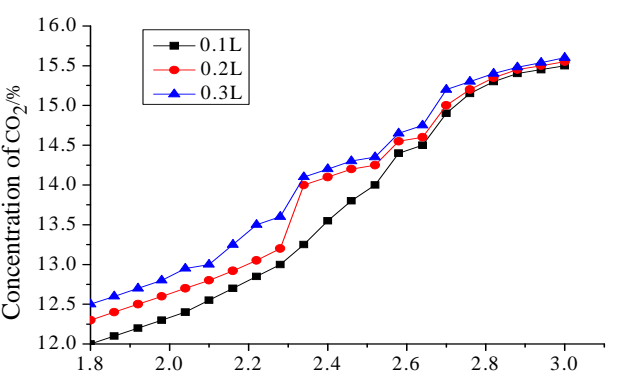

Distance from furnace exit to coal seam surface/m

FIGURE VI. $\mathrm{CO}_{2}$ DISTRIBUTION OF FURNACE OUTLET UNDER DIFFERENT OVERLAY LENGTH OF FRONT ARCH 


\section{2) Effect of front arch height on Combustion}

The temperature of the front arch under different front arch height is shown in figure 7 . It can be seen that the temperature of the front arch decreases with the increase of the height of the arch. The distribution of oxygen, hydrogen, carbon monoxide and carbon dioxide in the outlet of the furnace under different height of the front arch is shown in Figure 8, figure 9, figure 10 and Figure 11. It can be seen that with the increase of the height of the arch, the concentration of oxygen, hydrogen and carbon monoxide is decreasing, and the carbon dioxide concentration is on the rise. Therefore, the increase of the height of the arch has a positive effect on the reaction of combustible gas.

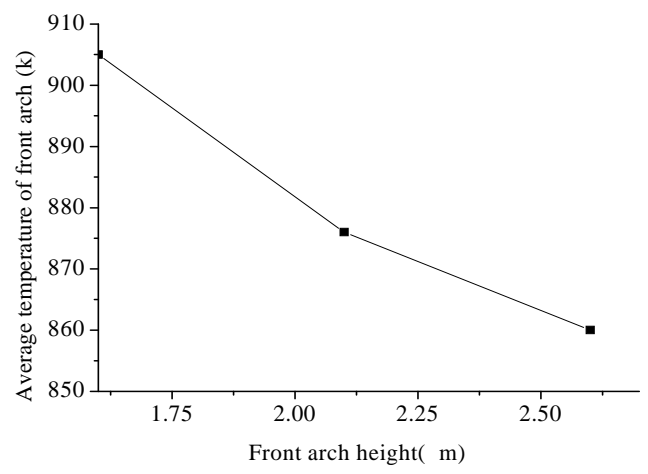

FIGURE VII. THE INFLUENCE OF THE FRONT ARCH HEIGHT ON THE FRONT ARCH TEMPERATURE

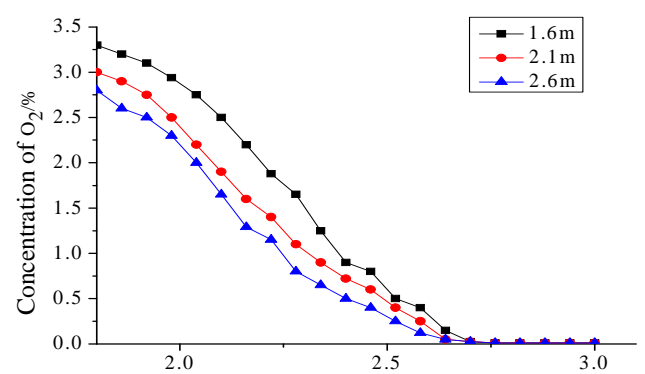

Distance from furnace exit to coal seam surface/m

FIGURE VIII. $\mathrm{O}_{2}$ DISTRIBUTION OF FURNACE OUTLET UNDER DIFFERENT FRONT ARCH HEIGHT

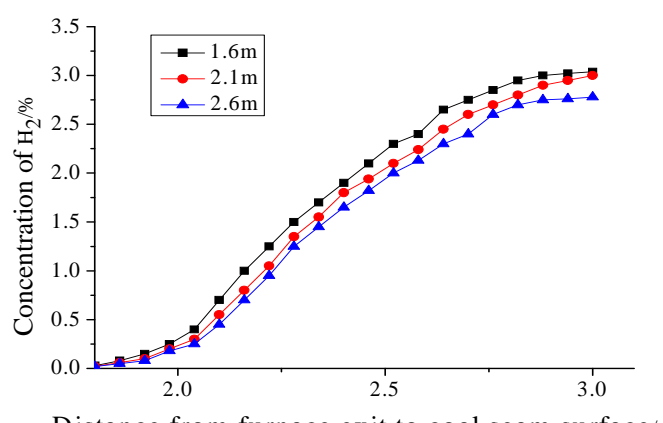

Distance from furnace exit to coal seam surface/m

FIGURE IX. $\mathrm{H}_{2}$ DISTRIBUTION OF FURNACE OUTLET UNDER DIFFERENT FRONT ARCH HEIGHT

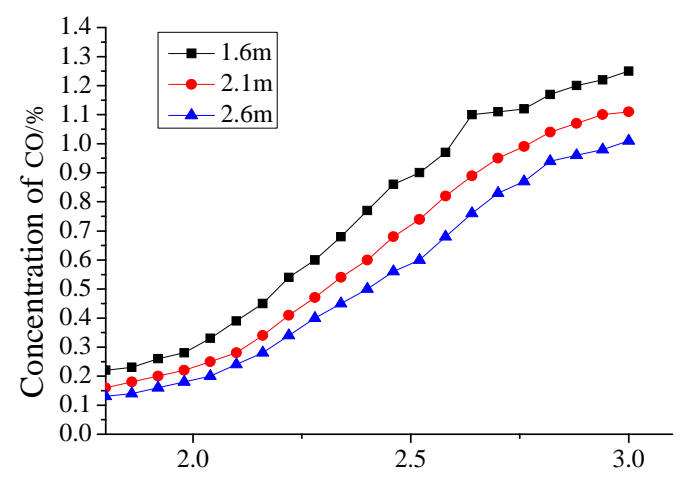

Distance from furnace exit to coal seam surface/m FIGURE X. CO DISTRIBUTION OF FURNACE OUTLET UNDER DIFFERENT FRONT ARCH HEIGHT

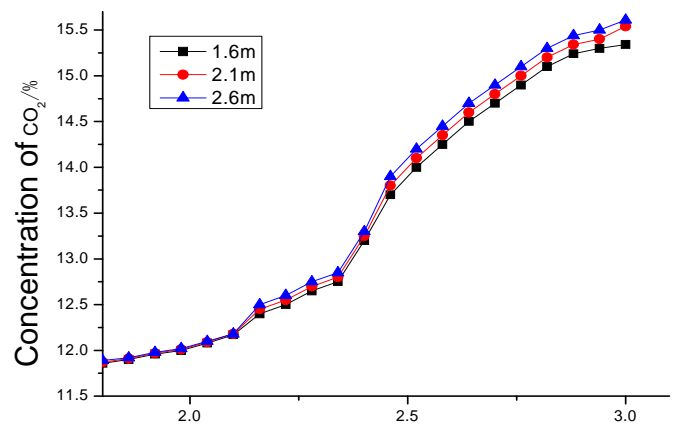

Distance from furnace exit to coal seam surface $/ \mathrm{m}$

FIGURE XI. $\mathrm{CO}_{2}$ DISTRIBUTION OF FURNACE OUTLET UNDER DIFFERENT FRONT ARCH HEIGHT

\section{B. Influence of Rear Arch on Combustion}

1) The influence of the overlay length of the rear arch on the combustion

The effect of the overlay length of the rear arch on the front arch temperature is shown in Figure 12. It can be seen that, with the increase of the rear arch overlay length, the temperature of the front arch increases. The effect of the overlay length of the rear arch on the incident radiation of the fuel layer surface is shown in Figure 13. With the extension of the length of the rear arch, more high temperature flue gas is directed to the front arch, and the temperature of the front arch region will rise, the radiant quantity of furnace arch and flue gas are increase, and then accelerate new fuel ignition. The incident radiation of the surface of the fuel layer in the middle of the arch is relatively large, the reason is that the increase of the length of the rear arch weakens the radiation of the high temperature flue gas on the upper water cooled wall, therefore, the incident radiation in the middle of the arch rises, and accelerate the fuel burn.

The distribution of oxygen, hydrogen, carbon monoxide and carbon dioxide in the outlet of the furnace under different length of rear arch overlay is shown in Figure 14, Figure 15, Figure 16, figure 17 . It can be seen that when the rear arch 
overlay length is $0.25 \mathrm{~L}$, the furnace outlet oxygen concentration up to $5 \%$, and when the rear arch covering a length of $0.65 \mathrm{~L}$, the furnace outlet oxygen concentration up to $4.1 \%$, compared with the overlay length of the rear arch is $0.25 \mathrm{~L}$ is reduced by $0.9 \%$.Under the furnace outlet, although part of hydrogen and carbon monoxide gas concentration increased with the increase of covering length of rear arch , but only a small part of them, these two kinds of gas at the exit of the furnace decreases with the length of the rear arch increases, indicating that the amount of combustible gas involved in combustion becomes more. The $\mathrm{CO} 2$ content of the furnace outlet is between $9.8 \%$ and $15.4 \%$ when the length of the rear arch overlay is $0.25 \mathrm{~L}$, when the length of the rear arch overlay is $0.65 \mathrm{~L}$, the carbon dioxide content of the furnace outlet is between $12.5 \%$ and $14.4 \%$. Therefore, it is beneficial for the combustion of combustible gas in the furnace to extend the length of the rear arch overlay.

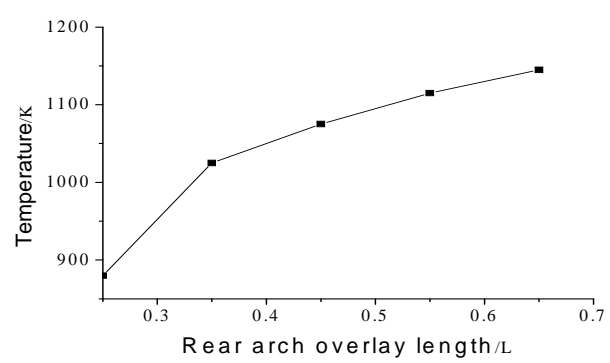

FIGURE XII. THE INFLUENCE OF THE LENGTH OF THE REAR ARCH ON THE TEMPERATURE OF THE FRONT ARCH

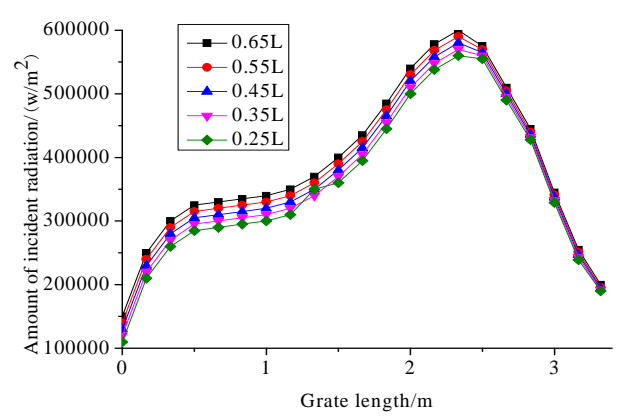

FIGURE XIII. THE INFLUENCE OF THE LENGTH OF THE REAR ARCH ON THE INCIDENT RADIATION OF THE FUEL LAYER SURFACE

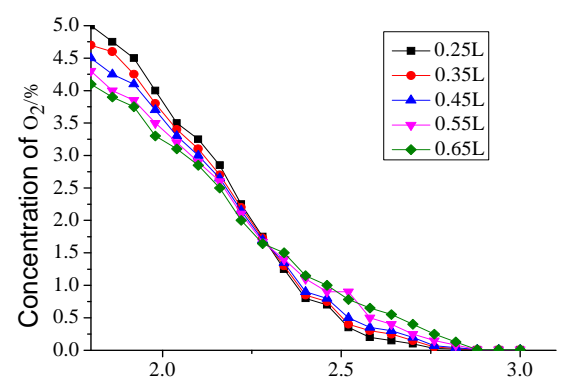

Distance from furnace exit to coal seam surface/m

FIGURE XIV. THE DISTRIBUTION OF OXYGEN IN THE OUTLET OF THE FURNACE WITH DIFFERENT LENGTH OF REAR ARCH OVERLAY

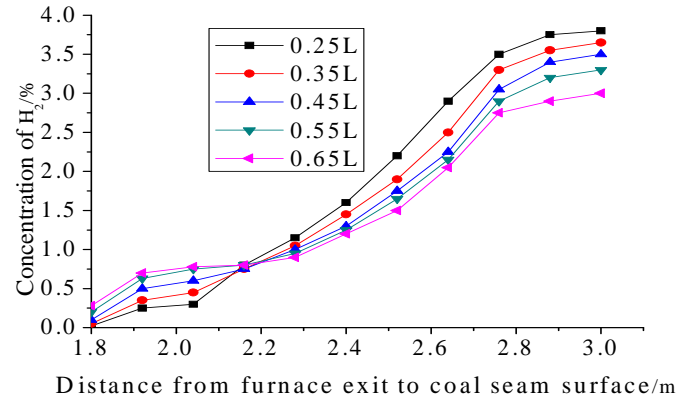

FIGURE XV. $\mathrm{H}_{2}$ DISTRIBUTION OF FURNACE OUTLET UNDER DIFFERENT REAR ARCH OVERLAY DIMENSIONS

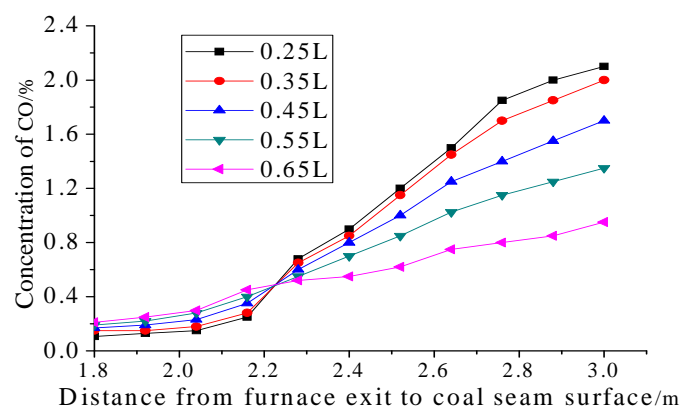

FIGURE XVI. THE CO DISTRIBUTION OF THE FURNACE OUTLET UNDER DIFFERENT REAR ARCH OVERLAY DIMENSIONS

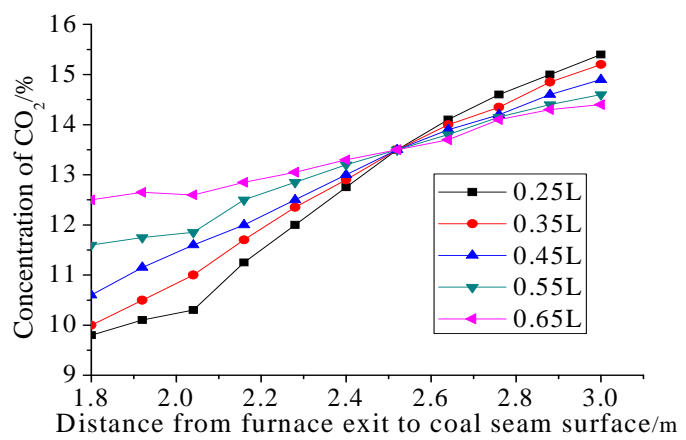

FIGURE XVII. THE $\mathrm{CO}_{2}$ DISTRIBUTION OF FURNACE OUTLET UNDER DIFFERENT LENGTH OF REAR ARCH OVERLAY

\section{2) Influence of the height of rear arch on Combustion}

The influence of the rear arch angle on the temperature of the front and rear arch is shown in Figure 18 and 19 respectively. The temperature of the front arch increases with the decrease of the rear arch angle, but the increase is not large. Therefore, the effect of rear arch angle decreases on ignition of fuel is very small. The rear arch temperature increased with the decrease of rear arch angle, the burn out effect of fuel is enhanced by rear arch.

The distribution of oxygen, hydrogen, carbon monoxide and carbon dioxide in the outlet of the furnace at different rear arch dip angle is shown in Figure 20, Figure 21, Figure 22 and figure 23. It can be find out that in the furnace outlet, the 
oxygen concentration highest up to $3.8 \%$ when the rear arch inclination is 6 degrees, the oxygen concentration highest up to $3.1 \%$ when rear arch inclination is 18 degrees, when the rear arch angle is 18 degrees, the oxygen concentration is reduced $0.7 \%$ compared with the rear arch angle of about 6 degrees. On the whole, the concentration of hydrogen and carbon monoxide gas in the furnace exit decreases with the decrease of the angle of the rear arch. At the exit of the furnace, the content of CO2 is between $9.5 \%$ and $14.73 \%$ when the rear arch angle is 6 degrees, and the CO2 content is between $9.6 \%$ and $15.1 \%$ when the rear arch angle is 18 degrees. Therefore, the increase of the rear arch angle is beneficial to the combustion of combustible gas.

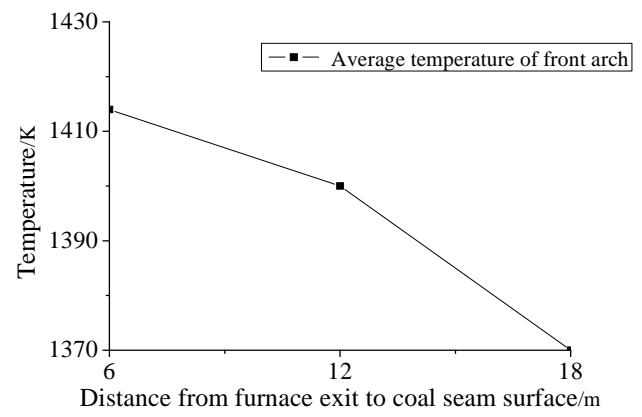

FIGURE XVIII. THE INFLUENCE OF THE REAR ARCH ANGLE ON THE TEMPERATURE OF THE FRONT ARCH

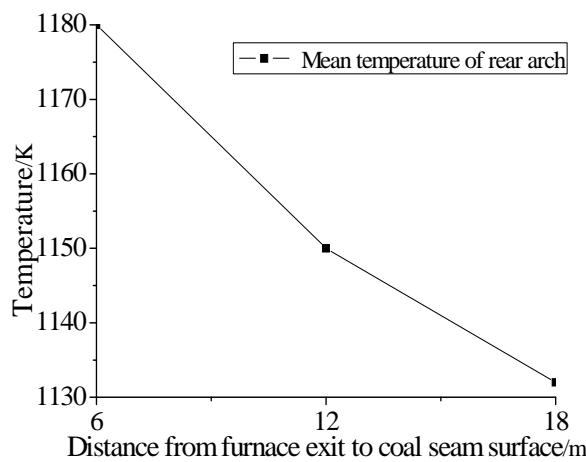

FIGURE XIX. THE INFLUENCE OF THE REAR ARCH ANGLE ON THE TEMPERATURE OF THE REAR ARCH

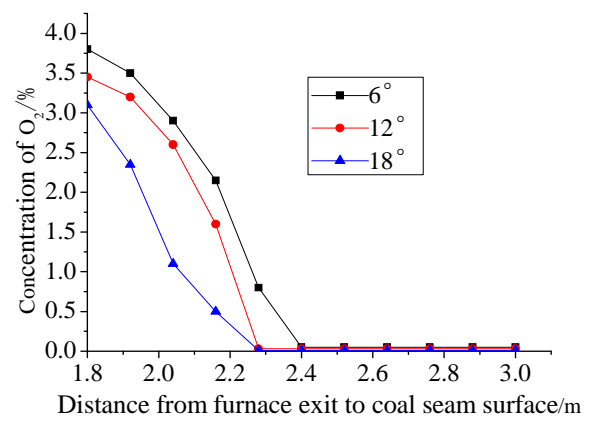

FIGURE XX. THE $\mathrm{O}_{2}$ DISTRIBUTION OF FURNACE OUTLET UNDER DIFFERENT REAR ARCH ANGLES

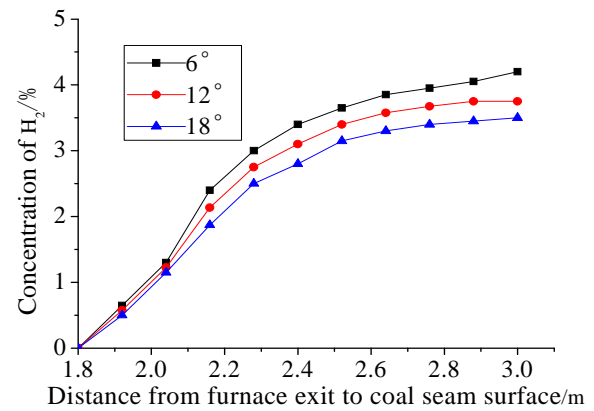

FIGURE XXI. THE $\mathrm{H}_{2}$ DISTRIBUTION OF FURNACE OUTLET UNDER DIFFERENT REAR ARCH ANGLES

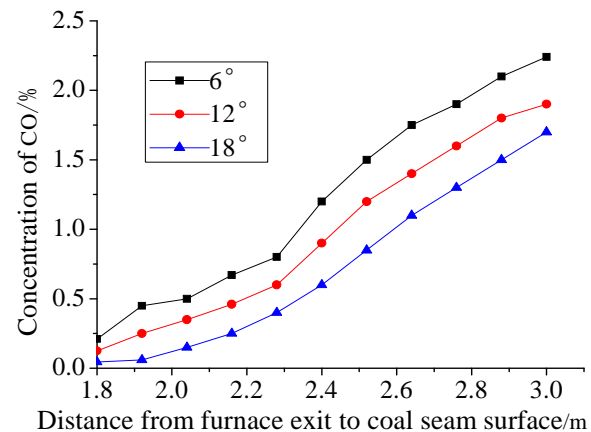

FIGURE XXII. THE CO DISTRIBUTION OF FURNACE OUTLET UNDER DIFFERENT REAR ARCH ANGLES

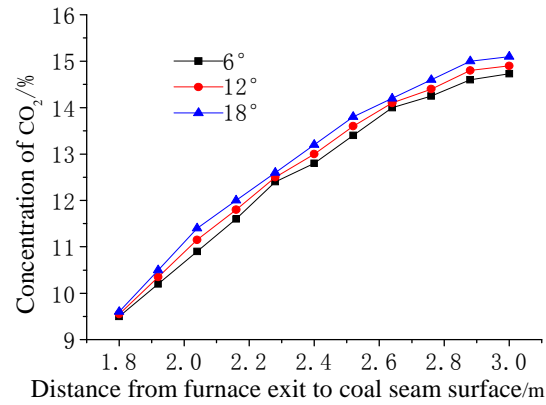

FIGURE XXIII. THE $\mathrm{CO}_{2}$ DISTRIBUTION OF FURNACE OUTLET UNDER DIFFERENT REAR ARCH ANGLES

\section{CONCLUSION}

In this paper, QXL1.4-0.7/95/70-AII type forced circulation hot water boiler is taken as the research object, the physical model is established and the mesh is divided through Gambit software, and Fluent software was used to simulate and calculate the gas flow and heat transfer in the furnace. Draw the following conclusions:

1) Effective length of rear arch becomes large with the rear arch overlay length extend, lead to the high temperature flue gas and radiation convection between front arch is enhancement, and then lead to the front arch temperature increases. What's more, it can contribute to the ignition of new 
fuels and combustion of combustible gases. The temperature of the front arch increases with the decrease of the angle of the rear arch, but the amplitude of the increase is not large, so the decrease of the rear arch angle has little effect on the ignition of the new fuel. The temperature of the rear arch increases with the decrease of the rear arch angle. With the increase of the temperature of the rear arch, the effect of the rear arch on the burning of the fuel will be strengthened. In comparison, the influence of the overlay length of the rear arch on the combustion is greater than the rear arch angle.

2) Through the analysis of the influence of the furnace arch structure on the chain grate combustion, it can be seen that the effect of the front arch on the combustion is not very large compared with the rear arch. The front arch structure mainly affects the ignition of the fuel, but the rear arch structure has an impact not only on the ignition, but also on the burnout.

\section{ACKNOWLEDGMENT}

This work was financially supported by the project supported by the A Research Project of Public Welfare Quality Testing Industry (201510067).

\section{REFERENCES}

[1] Gao, Jinsen, et al. "Numerical Simulation on Gas-Solid Two-Phase Turbulent Flow in FCC Riser Reactors (I) Turbulent Gas-Solid FlowReaction Model." Chinese Journal of Chemical Engineering 6.1(1998):16-24.].

[2] Jizhaug WANG. Analysis of the influence of boiler arch on furnace heat transfer. Diss. Dalian University of Technology, 2003.

[3] Jifeng CHU. Numerical simulation study on influence of arch and air distribution mode for combustion performance in reciprocating furnace. Diss. Harbin Institute of Technology, 2014.

[4] Jingru BAI, Qing WANG, Baizhong SUN, Xiangli LIU, Jian SUN. " Analysis of combustion characters in furnace for coal sootless combustion boiler." Environmental pollution control technology and equipment 7.8(2006):140-144.

[5] Huanqun QIAN,Zhengqing MIAO Numerical of air flow in arches of grate stokers." energy conservation 26.4(2007):20-21.

[6] Gupta, R. P., et al. "Ignition temperature of pulverized coal particles: Experimental techniques and coal-related influences 2 . Flame 79.3-4(1990):333-339.

[7] Zhou, L. X, et al. "Simulation of 3-D gas-particle flows and coal combustion in a tangentially fired furnace using a two-fluid-trajectory model." Powder Technology 125.2-3(2002):226-233.

[8] Biyikoglu, A. Mathematical modelling of a boiler with a fixed with a fixed bed coal combusion , [Ph. D. thesis], Ankara(in Turkish), Institute of Science and Technongy, Gazi University, 1993.

[9] Hobbs, Michael L., P. T. Radulovic, and L. D. Smoot. "Modeling fixedbed coal gasifiers." Aiche Journal 38.5(1992):681-702.

[10] Hobbs, M. L. P. T. Radulovic, D. L. Smoot, Modeling fixed-bed coal gasifers, AIChE Journal, 1992， 38(5):681-702.

[11] Radulovic, P. T. , Radulovic D. L. Smoot, Improved model fixedb coal combustion and gasification, Fuel, 1995, 74(4):582-594.

[12] Ghani, M. U. , P. T. , Radulovic, L. D. Smoot, an improved model for fixed bed coal combustion and gasification:Sensitivity analysis and applications, Fuel, 1996, 75(10):1213-1226.

[13] Hobbs, M. L. , P. T. Radulovic, L. D. Smoot, Combustion and gasification of coals in fixed-beds, Progress in Energy and Combustion Science, 1993, 19(6): 505-586.

[14] Ford, N. W. J., M. J. Cooke, and P. W. Sage. "Modelling of fixed bed combustion." Fuel Processing Technology 36.1-3(1993):55-63.
[15] Cooper, J., W.L.H. Hallett, Numerical model or packed-bed combustion of char particles, Chemical Engineering Science, 2000, 55(20): 44514460. 